\title{
Plasma levels of fibrinogen and ambulatory blood pressure monitoring: study in elderly patients
}

\author{
M Lugarà ${ }^{*}$, A Grembiale 1 , E Succurro ${ }^{1}$, F lorio ${ }^{1}$, V Caruso ${ }^{1}$, S Cufone ${ }^{1}$, E Pedace ${ }^{1}$, S Mastroianni ${ }^{1}$, M Ruffo ${ }^{1}$, \\ C Cloro $^{2}$, F Arturi $^{1}$
}

From de Senectute: Age and Health Forum

Catanzaro, Italy. 5-7 December 2009

\section{Background}

Fibrinogen, the precursor of fibrin in the coagulation cascade, is also a protein of the acute phase of inflammation, and it is the major determinant of plasma viscosity, all risk factors involved in the genesis of atherosclerotic vascular disease. The aim of this study was to evaluate the association between the fibrinogen plasma levels and blood pressure measured by ambulatory monitoring in 24 hours.

\section{Materials and methods}

In our study we examined 360 patients with ischemic heart disease and/or hypertensive heart disease. All patients underwent cardiovascular examination, laboratory tests, ambulatory blood pressure monitoring and 24-hour Holter-ECG. Our population was then divided into tertiles according to the plasma fibrinogen levels $\left(1^{\text {st }}\right.$ tertile $272+26 \mathrm{mg} / \mathrm{dl} ; 2^{\text {nd }}$ tertile $338+19 \mathrm{mg} / \mathrm{dl}$; $3^{\text {rd }}$ tertile $\left.468+86 \mathrm{mg} / \mathrm{dl}\right)$.

\section{Results}

Our data showed no statistically significant differences between the values of systolic and diastolic blood pressure (SPBC, DBPC) detected by mercury sphygmomanometer, in the $3^{\text {rd }}$ tertile of plasma fibrinogen than $2^{\text {nd }}$ and $1^{\text {st }}$ tertile. On the other hand, mean values of the systolic ambulatory blood pressure, of the 24 hours blood pressure (SBP 24h), of the day-time (SBPD) and night-time (SBPN) pressure were significantly higher in the $3^{\text {rd }}$ tertile than $2^{\text {nd }}$ or $1^{\text {st }}$ tertile of fibrinogen. Moreover, we observed a statistically significant reduction of the mean values of diastolic pressure of 24 hours (DBP24h), of diurnal (DBPD) and nocturnal (DBPN) pressure, resulting in significant increase in values of pulse pressure (PP), in the $3^{\text {rd }}$ tertile than $2^{\text {nd }}$ or $1^{\text {st }}$ tertile of fibrinogen. In conclusion, our data showed that in the elderly patients high plasma fibrinogen levels are significantly correlated with the values of systolic and diastolic ambulatory blood pressure monitoring and the mean values of heart-rate. Moreover, the analysis of individual tertiles showed a prevalence of atherosclerotic coronary disease significantly higher in the $3^{\text {rd }}$ tertile of fibrinogen $(76 \%$ vs. $55 \%$ and $35 \%, p=0001)$ than $2^{\text {nd }}$ and $1^{\text {st }}$ tertile.

\section{Conclusions}

Our data confirm that high levels of fibrinogen are associated with atherosclerotic coronary disease and represent a risk factor for cardiovascular disease in elderly patients.

\section{Author details}

'Dipartimento di Medicina Sperimentale e Clinica, Università degli Studi "Magna Graecia"di Catanzaro, Italy. ${ }^{2}$ Unità Operativa di Cardiologia, Ospedale Civile"SS Annunziata" di Cosenza, Italy.

Published: 19 May 2010

doi:10.1186/1471-2318-10-S1-A84

Cite this article as: Lugarà et al.: Plasma levels of fibrinogen and ambulatory blood pressure monitoring: study in elderly patients. BMC Geriatrics 2010 10(Suppl 1):A84. 